\title{
Prevalence of Eye Diseases in South Korea: Data from the Korea National Health and Nutrition Examination Survey 2008-2009
}

\author{
Kyung-Chul Yoon ${ }^{1}$, Gui-Hyeong Mun ${ }^{1}$, Sang-Duck Kim ${ }^{2}$, Seung-Hyun Kim ${ }^{3}$, Chan Yun Kim ${ }^{4}$, Ki Ho Park ${ }^{5}$ \\ Young Jeung Park ${ }^{6}$, Seung-Hee Baek ${ }^{7}$, Su Jeong Song ${ }^{8}$, Jae Pil Shin ${ }^{9}$, Suk-Woo Yang ${ }^{10}$, Seung-Young Yu ${ }^{11}$, \\ Jong Soo Lee ${ }^{12}$, Key Hwan Lim ${ }^{13}$, Hye-Jin Park ${ }^{14}$, Eun-Young Pyo ${ }^{14}$, Ji-Eun Yang ${ }^{14}$, Young-Taek Kim ${ }^{14}$, \\ Kyung-Won $\mathrm{Oh}^{14}$, Se Woong Kang ${ }^{15}$ \\ ${ }^{1}$ Department of Ophthalmology, Chonnam National University Hospital, Chonnam National University Medical School, Gwangju, Korea \\ ${ }^{2}$ Department of Ophthalmology, Wonkwang University College of Medicine, Iksan, Korea \\ ${ }^{3}$ Department of Ophthalmology, Korea University College of Medicine, Ansan, Korea \\ ${ }^{4}$ Institute of Vision Research, Department of Ophthalmology, Yonsei University College of Medicine, Seoul, Korea \\ ${ }^{5}$ Department of Ophthalmology, Seoul National University College of Medicine, Seoul, Korea \\ ${ }^{\sigma}$ Department of Ophthalmology, Cheil Eye Hospital, Daegu, Korea \\ ${ }^{7}$ Department of Ophthalmology, Kim's Eye Hospital, Konyang University College of Medicine, Seoul, Korea \\ ${ }^{8}$ Department of Ophthalmology, Kangbuk Samsung Hospital, Sungkyunkwan University School of Medicine, Seoul, Korea \\ ${ }^{9}$ Department of Ophthalmology, Kyungpook National University School of Medicine, Daegu, Korea \\ ${ }^{10}$ Department of Ophthalmology, The Catholic University of Korea College of Medicine, Seoul, Korea \\ ${ }^{11}$ Department of Ophthalmology, Kyung Hee University School of Medicine, Seoul, Korea \\ ${ }^{12}$ Department of Ophthalmology, Pusan National University College of Medicine, Busan, Korea \\ ${ }^{13}$ Department of Ophthalmology, Ewha Womans University School of Medicine, Seoul, Korea \\ ${ }^{14}$ Division of Chronic Disease Surveillance, Korea Centers for Disease Control \& Prevention, Seoul, Korea \\ ${ }^{15}$ Department of Ophthalmology, Samsung Medical Center, Sungkyunkwan University School of Medicine, Seoul, Korea
}

Purpose: The aim of this study is to report on preliminary data regarding the prevalence of major eye diseases in Korea.

Methods: We obtained data from the Korea National Health and Nutrition Examination Survey, a nation-wide cross-sectional survey and examinations of the non-institutionalized civilian population in South Korea $(\mathrm{n}=$ 14,606), conducted from July 2008 to December 2009. Field survey teams included an ophthalmologist, nurses, and interviewers, traveled with a mobile examination unit and performed interviews and ophthalmologic examinations.

Results: The prevalence of visual impairment, myopia, hyperopia and astigmatism in participants over 5 years of age was $0.4 \pm 0.1 \%, 53.7 \pm 0.6 \%, 10.7 \pm 0.4 \%$, and $58.0 \pm 0.6 \%$, respectively. The prevalence of strabismus and blepharoptosis in participants over 3 years of age was $1.5 \pm 0.1 \%$ and $11.0 \pm 0.8 \%$, respectively. In participants over 40 years of age, the prevalence of cataract, pterygium, early and late age-related macular degeneration, diabetic retinopathy and glaucoma was $40.2 \pm 1.3 \%, 8.9 \pm 0.5 \%, 5.1 \pm 0.3 \%, 0.5 \pm 0.1 \%, 13.4 \pm 1.5 \%$, and $2.1 \pm$ $0.2 \%$, respectively.

Conclusions: This is the first nation-wide epidemiologic study conducted in South Korea for assessment of the prevalence of eye diseases by both the Korean Ophthalmologic Society and the Korea Center for Disease Control and Prevention. This study will provide preliminary information for use in further investigation, prevention, and management of eye diseases in Korea.

Key Words: Epidemiology, Eye diseases, Korea, Korea National Health and Nutrition Examination Survey, Prevalence 
Epidemiological studies provide information on the prevention, treatment, and minimization of the impact of diseases on society. In the past two decades, a wide range of epidemiologic studies in ophthalmology have provided important information on the pattern of visual impairment and the major eye diseases that cause such vision loss [1]. Although several epidemiological studies of several age-related eye diseases (e.g., glaucoma, age-related macular degeneration, and cataract) have been conducted in Korea [2-4], these studies were hospital-based or were conducted primarily in urban areas. Data on the prevalence of diseases based on the number of hospital visits or surveys conducted in limited areas are easy to obtain; however, substantial differences may exist between such data and that obtained in large-scale population studies, which are more accurate and can represent entire populations.

Large-scale population-based studies conducted over the past two decades in many countries, including the United States [5-14], Western Europe [15-17], Australia [18-21], Japan [22-26], Singapore [27-30], and China [31-35], have been used to guide public health policy and plan preventive strategies. However, these studies were conducted mostly with regard to major age-related eye diseases, such as cataract, glaucoma, age-related macular degeneration, and diabetic retinopathy, which are major causes of vision loss. Nation-wide epidemiological studies of all age groups for the prevalence of common eye diseases have not been performed.

The Korea Center for Disease Control and Prevention (CDC) conducted a series of Korea National Health and Nutrition Examination Surveys (KNHANES) in 1998, 2001, 2005 and 2007-2009 for examination of the general health and nutrition status of Koreans. As of the fourth KNHANES (2007-2009), an annual total of 4,600 households were selected, and the participating household members were interviewed regarding health and nutrition and underwent a basic health examination that included blood pressure measurements, blood and urine collection, a pulmonary function test, and a dental examination. Since the Korean Ophthalmologic Society has participated in this survey since 2008, ophthalmologic interviews and examinations were also conducted with the same participants.

The purpose of this study is to investigate the national prevalence of common eye diseases in South Korea based on the survey data obtained from the KNHANES and to analyze the prevalence of diseases according to age and gender. Data

Received: July 18, 2011 Accepted: September 23, 2011

Corresponding Authors: Se Woong Kang, MD, PhD. Department of Ophthalmology, Samsung Medical Center, Sungkyunkwan University School of Medicine, \#50 Irwon-dong, Gangnam-gu, Seoul 135-710, Korea. Tel: 82-2-3410-3562, Fax: 82-2-3410-0074, E-mail: swkang@skku.edu. Kyung Won Oh, PhD. Division of Chronic Disease Surveillance, Korea Centers for Disease Control \& Prevention, \#187 Osongsaengmyeong 2-ro, Gangoe-myeon, Cheongwon 363-951, Korea. Tel: 82-43-719-7460, Fax: 82-43-719-7527, E-mail: kwoh27@korea.kr obtained from KNHANES may offer further insight into the etiology, ethnic differences, and public health impact of the most common eye diseases affecting Korean people living in Asia.

\section{Materials and Methods}

\section{Study design and population}

The KNHANES is an ongoing population-based, crosssectional epidemiological survey conducted in South Korea. Annually, 4,000 households in 200 enumeration districts were selected by a panel to represent the civilian, non-institutionalized South Korean population using the stratified, multistage clustered sampling method based on the 2005 National Census Data. In KNHANES, sample design and size are estimated so that annual survey results represent the whole population in Korea. Therefore, annual survey results can be used as statistics to represent the overall Korean population. All members of each selected household were asked to participate in the survey, and the rate of participation in the past several cycles ranged from $79 \%$ to $84 \%$. From July 2008, ophthalmologic interviews and examinations have been conducted. All examination and health interviews were conducted by trained teams in mobile centers, while nutrition surveys were performed in individual households.

This survey is aimed to determine the prevalence of the following vision status and common eye diseases in a population-based sample of Koreans: visual impairment and blindness, refractive errors, strabismus, blepharoptosis, cataract, pterygium, diabetic retinopathy, age-related macular degeneration (AMD), and glaucoma. The ophthalmologic survey was designed to be conducted over 5 years from 2008 to 2013. The present study includes interim data from a survey conducted from July 2008 to December 2009.

\section{Examination procedures}

Examination procedures were stratified according to age group. Participants aged 3 to 4 years old only underwent testing for strabismus and blepharoptosis. Autorefraction and visual acuity testing and testing for strabismus and blepharoptosis were performed among the participants ranging in age from 5 to 18 years old. The participants over 19 years of age underwent full ocular examinations, including autorefraction and visual acuity testing, testing for strabismus and blepharoptosis, slit lamp examinations, measurement of intraocular pressure (IOP), and fundus photographs. IOP was measured with a Goldmann applanation tonometer. For participants meeting the glaucoma suspicion criteria, frequency doubling perimetry (FDT) was carried out. Phamacological pupil dilatation was performed for participants who had a history of diabetes mellitus or random blood glucose level of $200 \mathrm{mg} / \mathrm{dL}$ or higher and/or fundus photograph suspected di- 


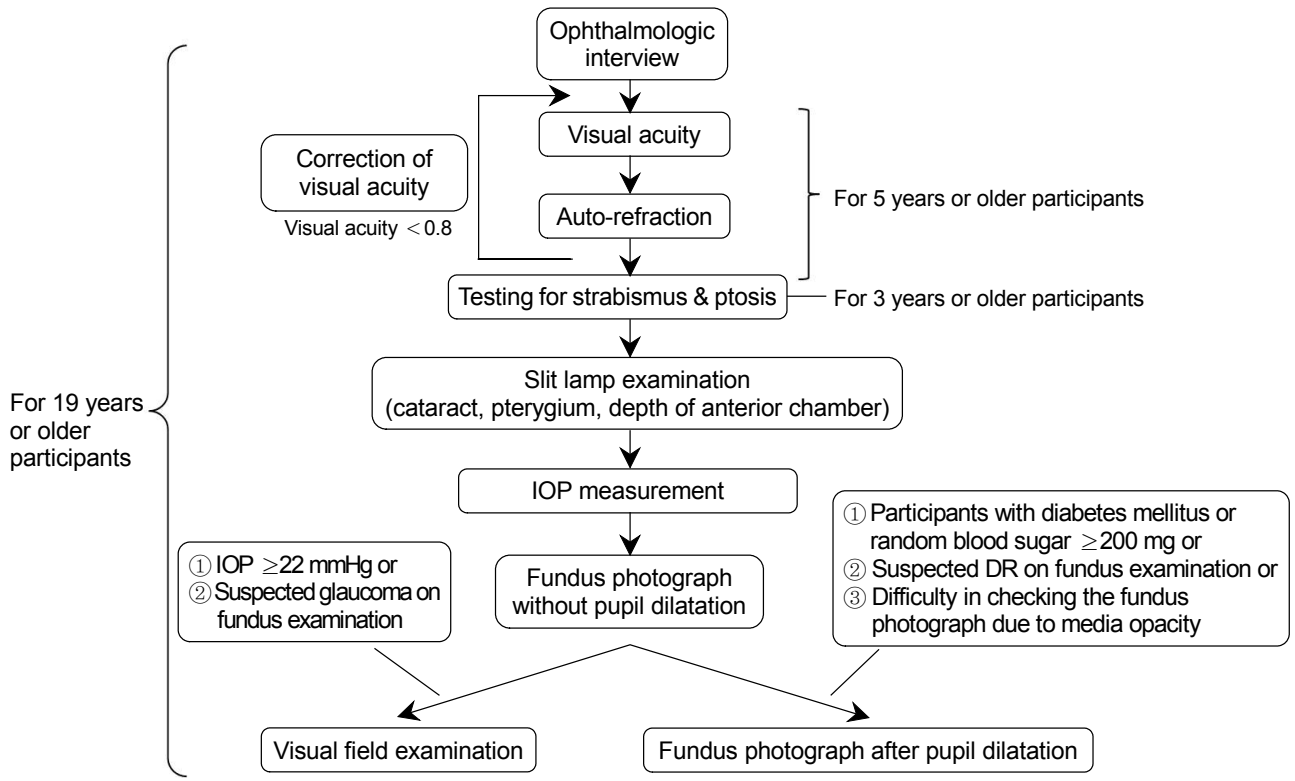

Fig. 1. Ophthalmologic examination flowchart for Korea National Health and Nutrition Examination Surveys. IOP = intraocular pressure; DR $=$ diabetic retinopathy. abetic retinopathy and/or difficulty obtaining a fundus photograph due to media opacity (Fig. 1). All procedures described above except for fundus photography were performed before pupil dilatation.

\section{Examination methods and definition of eye diseases}

\section{1) Questionnaire}

A detailed interviewer-administered questionnaire was administered for collection of relevant sociodemographic and medical information. Collected data included marital status, education, occupation, current housing status, lifestyle factors (including cigarette smoking history), optical symptoms, systemic medical and surgical history, and family history of eye diseases.

\section{2) Visual acuity}

Uncorrected visual acuity and/or best-corrected distance visual acuity (BCVA) were measured at a distance of $4 \mathrm{~m}$ using an international standard vision chart based on the LogMAR Scale (Jin's vision chart, Seoul, Korea) [36]. Visual impairment was defined as a BCVA of 0.32 or worse in the best eye. Blindness was defined as BCVA of 0.02 or worse in the right or left eye.

\section{3) Autorefraction}

An autorefractor-keratometer (KR8800; Topcon, Tokyo, Japan) was used for all measurement of refraction, which were converted to spherical equivalents calculated as the spherical value plus half of the astigmatic value. Myopia was defined as an spherical equivalents of worse than -0.75 diopters (D). Hyperopia was defined as spherical equivalents of worse than $+1.0 \mathrm{D}$. Astigmatism was defined as a cylindrical error worse than $+0.75 \mathrm{D}$.

\section{4) Strabismus}

Testing for strabismus included the cover-uncover test, prism and alternate cover test, and/or Krimsky test. Strabismus was defined as a manifest or latent ocular deviation at distance or near fixation with or without spectacle correction, esodeviation of 10 or more prism diopters, exodeviation of 15 or more prism diopters, or any vertical deviation.

\section{5) Blepharoptosis}

Blepharoptosis was defined as presentation of a marginal reflex distance $\left(M R D_{1}\right)$ of $2 \mathrm{~mm}$ or less. Measurement of $\mathrm{MRD}_{1}$ was performed as follows: Positioned at the physician's eye level, participants were asked to look straight ahead and relax while focusing at a distance target. Shining the penlight into the participant's eye, the distance from the corneal light reflex to the upper eyelid margin was measured in millimeters.

\section{6) Slit lamp examination}

A structured slit-lamp examination (Haag-Streit model BQ-900; Haag-Streit AG, Koeniz, Switzerland) was performed by study ophthalmologists. The slit lamp examination was performed for determination of diseases in the anterior segment of the eye (e.g., pterygium and cataract) and measurement of the IOP and anterior chamber depth using the Van Herick method [37]. Cataract was defined as a nuclear, cortical, or posterior subcapsular cataract in at least one eye. Pseudophakic and aphakic eyes were included as operated cataracts for the purpose of statistical analysis. A pterygium was defined as a radially oriented fibrovascular lesion crossing over the nasal or temporal limbus. Grading was based on the visibility of the underlying episcleral blood vessels [38]. 


\section{7) Fundus photography}

A digital nonmydriatic fundus camera (TRC-NW6S, Topcon) and a Nikon D-80 digital camera (Nikon, Tokyo, Japan) were used to obtain the digital fundus images. Digital images were captured from all participants 19 years of age and older under physiological mydriasis. For each participant, one $45^{\circ}$ nonmydriatic digital retinal image centered on the fovea (field 2 ) was taken per eye ( 2 images per person in total). Each image was graded twice (a preliminary grade and a detailed grade) using the grading protocol of the International Age-related Maculopathy Epidemiological Study Group [39]. Optic nerve configuration and any retinal pathologic findings were recorded. Patients were defined as having early AMD if they met any one of the following criteria: (1) the presence of soft indistinct drusen or reticular drusen, or (2) the presence of hard or soft distinct drusen with pigmentary abnormalities (increased pigmentation or hypopigmentation of the retinal pigment epithelium) in the absence of signs of late AMD. Late AMD included the presence of signs of wet AMD or geographic atrophy. Wet AMD was defined as retinal pigment epithelial detachment or serous detachment of the sensory retina, subretinal or sub-RPE hemorrhages, and subretinal fibrous scars. Geographic atrophy was defined as a circular discrete area (of 175 microns in diameter) of retinal depigmentation with visible choroidal vessels, in the absence of signs of wet AMD.

In participants who had a history of diabetes mellitus or random blood glucose level of $200 \mathrm{mg} / \mathrm{dL}$ or higher and/or suspicion of diabetic retinopathy in nonmydriatic fudndus photography, 7 standard photographs from the Early Treatment for Diabetic Retinopathy Study were obtained from each eye after pharmacological pupil dilatation [40,41]. Diabetic retinopathy was defined as the presence of 1 or more retinal microaneurysms or retinal blot hemorrhages with or without more severe lesions (hard exudates, soft exudates, intraretinal microvascular abnormalities, venous bleeding, new retinal vessels, and fibroproliferations) [42,43]. The prevalence of diabetic retinopathy was estimated in persons with diabetes mellitus.

\section{8) Visual field test}

FDT (Humphrey Matrix; Carl Zeiss Meditec Inc., Dublin, CA, USA) testing with the screening program N-30-1 was performed if the participants had elevated IOP $\geq 22 \mathrm{mmHg}$ or a glaucomatous optic disc. FDT testing was repeated once if deemed unreliable. Patients were defined as having primary open angle glaucoma (POAG) if they met any one of the following category I or category II diagnostic criteria [44].

\section{9) Category I diagnosis}

The presence of FDT testing results, fixation error and false positive error $\leq 1$ : (1) elevated IOP $\geq 22 \mathrm{mmHg}$ or (2) glaucomatous optic disc (loss of neuroretinal rim with vertical or horizontal cup-disc ratio $\geq 0.6$ or presence of optic disc hemorrhage or presence of retinal nerve fiber layer defect or asymmetry of vertical cup-disc ratio $\geq 0.2$ ), (3) the presence of an abnormal FDT testing result (at least one location of reduced sensitivity) and (4) the presence of an open angle (peripheral anterior chamber depth $>1 / 4$ corneal thickness)

\section{0) Category II diagnosis}

Absence of FDT testing results or fixation error or false positive error $\geq 2$, (1) the presence of an open angle (peripheral anterior chamber depth $>1 / 4$ corneal thickness) and (2) loss of neuroretinal rim with vertical cup-disc ratio $\geq 0.9$, (3) asymmetry of vertical cup-disc ratio $\geq 0.3$ or (4) the presence of retinal nerve fiber layer defect and violation of the ISNT rule.

Normal tension glaucoma (NTG) was defined using the same criteria for POAG with IOP $\leq 21 \mathrm{mmHg}$. Primary angle closure glaucoma (PACG) was diagnosed when all of the following four criteria were met: (1) the presence of a narrow, occludable angle (peripheral anterior chamber depth $<1 / 4$ corneal thickness), (2) elevated IOP $\geq 22 \mathrm{mmHg}$, (3) glaucomatous optic disc (loss of neuroretinal rim with vertical or horizontal cup-disc ratio $\geq 0.6$ or the presence of optic disc hemorrhage or retinal nerve fiber layer defect), and (4) the presence of an abnormal FDT testing result (at least one location of reduced sensitivity) and fixation error, false positive error $\leq 1$.

\section{Quality control and data analysis}

A total of 308 surveys were conducted by four survey teams within a time span of 77 weeks. Each survey team included one ophthalmologist, one otolaryngologist, one dentist, three nurses, two interviewers, and one coordinator. The team moved with a mobile examination unit to pre-assigned locations and performed surveys for three days. A total of 199 ophthalmology residents or ophthalmologists from 66 training hospitals participated in this project as ophthalmologic examiners.

The quality of the survey was verified by the Epidemiologic Survey Committee of the Korean Ophthalmologic Society. Training of participating residents was periodically performed by acting staff members of the National Epidemiologic Survey Committee of the Korean Ophthalmologic Society. Data were collected using a combination of paper and digital formats. Imaging data, including fundus photographs, were retrieved directly from the imaging equipment and stored in their respective computers. All variables of interest were entered into a password-protected Microsoft Office Access database by a data entry clerk. For all digital information, original data were copied into external hard disks daily and written onto DVDs for storage.

Statistical analyses were performed using SAS ver. 9.2 (SAS Institute, Cary, NC, USA). All estimates were obtained using the sample weight adjusted for oversampling, nonresponse and the Korean population in 2008 to 2009, and standard errors of estimates were estimated accounting for the complex design of the survey. Prevalence estimates for all outcomes were performed for the overall sample and then 
in age- and gender-stratified groups. Chi-square tests were used for analysis of differences in prevalence between genders. Logistic regression was used for analysis of differences in prevalence among age groups.

\section{Results}

During the period from July 2008 to December 2009, a total of 14,606 participants from 5,986 households were recruited and underwent an eye examination. Ages of the study participants ranged from 3 to 95 years of age: 6,580 were men and 8,026 were women. Table 1 shows the age and gender distributions of the study population.

\section{Visual impairment and blindness}

The overall prevalence of visual impairment was $0.4 \pm$ $0.1 \%(0.3 \pm 0.1 \%$ in males, $0.5 \pm 0.1 \%$ in females $)$ (Table 2$)$, while that in participants over 40 years of age was $0.9 \pm 0.1 \%$ $(0.6 \pm 0.1 \%$ in males, $1.1 \pm 0.2 \%$ in females $)$ and was higher in females than males $(p=0.04)$. The prevalence of visual impairment in participants over 70 years of age was $3.8 \pm$ $0.7 \%$ (2.9 $\pm 0.8 \%$ in males, $4.4 \pm 0.9 \%$ in females $)$ and showed a significant increase with age $(p<0.01)$. The prevalence of blindness in either eye of participants over 65 years of age was $0.2 \pm 0.1 \%(0.3 \pm 0.2 \%$ in males, $0.1 \pm 0.1 \%$ in fe-

Table 1. Number of participants according to age and gender

\begin{tabular}{crrr}
\hline Age group (yr) & Male & Female & \multicolumn{1}{c}{ Total } \\
\hline $3-4$ & 203 & 174 & 377 \\
$5-18$ & 1,608 & 1,458 & 3,066 \\
$19-29$ & 692 & 869 & 1,561 \\
$30-39$ & 905 & 1,254 & 2,159 \\
$40-49$ & 954 & 1,265 & 2,219 \\
$50-59$ & 804 & 1,062 & 1,866 \\
$60-69$ & 784 & 1,023 & 1,807 \\
$\geq 70$ & 630 & 921 & 1,551 \\
Total & 6,580 & 8,026 & 14,606 \\
\hline
\end{tabular}

males), and there were no statistically significant differences in relation to gender $(p>0.05)$.

\section{Refractive errors}

The overall prevalence of myopia was $53.7 \pm 0.6 \%(54.3 \pm$ $0.8 \%$ in males, $53.1 \pm 0.7 \%$ in females) (Table 3 ). The prevalence of myopia in the group of participants ranging in age from 12 to 18 was $78.8 \pm 1.3 \%(77.9 \pm 1.7 \%$ in males, $79.9 \pm$ $1.7 \%$ in females) and was highest among the age groups $(p<$ $0.01)$. The prevalence of myopia was higher in females than in males in the 19 to 29 and over 70 years age groups $(p<$ 0.05 for both).

The overall prevalence of hyperopia was $10.7 \pm 0.4 \%(9.4$ $\pm 0.4 \%$ in males, $12.0 \pm 0.5 \%$ in females) (Table 3 ). In the group of participants ranging in age from 5 to 11, the prevalence of hyperopia was $5.3 \pm 0.6 \%$ and then decreased with age. From the group of participants ranging in age from 40 to 49 , the prevalence of hyperopia again increased with age. The prevalence of hyperopia in the group of participants ranging in age from 60 to 69 and in the age group over 70 years was $43.8 \pm 1.4 \%$ and $47.1 \pm 1.5 \%$, respectively. In all age groups, there was no statistically significant difference in relation to gender $(p>0.05)$.

The overall prevalence of astigmatism was $58.0 \pm 0.6 \%$ $(57.6 \pm 0.8 \%$ in males, $58.4 \pm 0.7 \%$ in females) (Table 3$)$, while that in the 70 years or older age group was $92.0 \pm 0.8 \%$ $(92.9 \pm 1.2 \%$ in males, $91.5 \pm 1.1 \%$ in females), illustrating a significant increase with age $(p<0.01)$. In the group of participants ranging in age from 30 to 39 , the prevalence of astigmatism was higher in males than in females $(p<0.01)$.

\section{Strabismus}

The overall prevalence of strabismus was $1.5 \pm 0.1 \%(1.5$ $\pm 0.2 \%$ in males, $1.5 \pm 0.2 \%$ in females) (Table 4$)$. The prevalence of strabismus in participants over 40 years of age was $1.4 \pm 0.2 \%(1.5 \pm 0.2 \%$ in males, $1.2 \pm 0.2 \%$ in females $)$. In the group of participants ranging in age from 3 to 5 years, the prevalence of strabismus was $1.8 \pm 0.7 \%(0.5 \pm 0.4 \%$ in

Table 2. Prevalence of visual impairment according to age and gender

\begin{tabular}{|c|c|c|c|c|c|c|c|c|c|c|}
\hline \multirow{2}{*}{ Age group (yr) } & \multicolumn{3}{|c|}{ Total } & \multicolumn{3}{|c|}{ Male } & \multicolumn{3}{|c|}{ Female } & \multirow{2}{*}{$p$-value } \\
\hline & No & Prev (\%) & SE & No & Prev (\%) & SE & No & Prev (\%) & SE & \\
\hline Total & 13,702 & 0.4 & $(0.1)$ & 6,171 & 0.3 & $(0.1)$ & 7,531 & 0.5 & $(0.1)$ & \\
\hline $5-18$ & 2,993 & 0.0 & $(-)$ & 1,571 & 0.0 & $(-)$ & 1,422 & 0.0 & $(-)$ & \\
\hline $19-29$ & 1,530 & 0.0 & $(-)$ & 679 & 0.0 & $(-)$ & 851 & 0.0 & $(0.1)$ & \\
\hline $30-39$ & 2,117 & 0.2 & $(0.1)$ & 88 & 0.3 & $(0.2)$ & 1,230 & 0.1 & $(0.1)$ & 0.08 \\
\hline $40-49$ & 2,178 & 0.1 & $(0.1)$ & 936 & 0.2 & $(0.1)$ & 1,242 & 0.0 & $(-)$ & \\
\hline $50-59$ & 1,824 & 0.3 & $(0.2)$ & 790 & 0.3 & $(0.2)$ & 1,034 & 0.4 & $(0.2)$ & 0.82 \\
\hline $60-69$ & 1,717 & 1.2 & $(0.3)$ & 746 & 0.9 & $(0.3)$ & 971 & 1.5 & $(0.4)$ & 0.18 \\
\hline$\geq 70$ & 1,343 & 3.8 & $(0.7)$ & 562 & 2.9 & $(0.8)$ & 781 & 4.4 & $(0.9)$ & 0.17 \\
\hline
\end{tabular}

Visual impairment was defined as a best-corrected distance visual acuity of 0.32 or worse in the best eye.

No $=$ number of participants; Prev = prevalence; $\mathrm{SE}=$ standard error. 
Table 3. Prevalence of refractive errors according to age

\begin{tabular}{|c|c|c|c|c|c|c|c|c|c|}
\hline \multirow{2}{*}{ Age group (yr) } & \multicolumn{3}{|c|}{ Myopia } & \multicolumn{3}{|c|}{ Hyperopia } & \multicolumn{3}{|c|}{ Astigmatism } \\
\hline & No & Prev (\%) & SE & No & Prev (\%) & SE & No & Prev (\%) & SE \\
\hline Total & 13,636 & 53.7 & $(0.6)$ & 13,636 & 10.7 & $(0.4)$ & 13,636 & 58.0 & $(0.6)$ \\
\hline $5-11$ & 1,560 & 50.0 & (1.5) & 1,560 & 5.3 & $(0.6)$ & 1,560 & 38.7 & (1.4) \\
\hline $12-18$ & 1,429 & 78.8 & (1.3) & 1,429 & 2.5 & $(0.4)$ & 1,429 & 61.6 & (1.6) \\
\hline $19-29$ & 1,529 & 75.3 & (1.2) & 1,529 & 1.9 & $(0.4)$ & 1,529 & 53.9 & (1.4) \\
\hline $30-39$ & 2,091 & 67.4 & $(1.2)$ & 2,091 & 1.1 & $(0.3)$ & 2,091 & 49.5 & (1.3) \\
\hline $40-49$ & 2,147 & 51.1 & (1.3) & 2,147 & 3.1 & $(0.4)$ & 2,147 & 51.8 & (1.4) \\
\hline $50-59$ & 1,786 & 29.3 & (1.3) & 1,786 & 16.5 & $(1.0)$ & 1,786 & 63.0 & (1.3) \\
\hline $60-69$ & 1,702 & 18.2 & (1.1) & 1,702 & 43.8 & (1.5) & 1,702 & 79.4 & (1.1) \\
\hline$\geq 70$ & 1,392 & 28.4 & $(1.2)$ & 1,392 & 47.1 & (1.5) & 1,392 & 92.0 & $(0.8)$ \\
\hline
\end{tabular}

Myopia was defined as spherical equivalents of worse than -0.75 diopter. Hyperopia was defined defined as spherical equivalents of worse than +1.0 diopter. Astigmatism was defined as a cylindrical error worse than +0.75 diopter.

No $=$ number of participants; Prev $=$ prevalence; $\mathrm{SE}=$ standard error .

Table 4. Prevalence of strabismus according to age and gender

\begin{tabular}{|c|c|c|c|c|c|c|c|c|c|c|}
\hline \multirow{2}{*}{ Age group (yr) } & \multicolumn{3}{|c|}{ Total } & \multicolumn{3}{|c|}{ Male } & \multicolumn{3}{|c|}{ Female } & \multirow{2}{*}{$p$-value } \\
\hline & No & Prev $(\%)$ & SE & No & Prev (\%) & SE & No & Prev (\%) & SE & \\
\hline Total & 14,464 & 1.5 & $(0.1)$ & 6,517 & 1.5 & $(0.2)$ & 7,947 & 1.5 & $(0.2)$ & 0.93 \\
\hline $3-5$ & 583 & 1.8 & $(0.7)$ & 314 & 0.5 & $(0.4)$ & 269 & 3.4 & (1.4) & 0.01 \\
\hline $6-11$ & 1,385 & 1.8 & $(0.3)$ & 725 & 1.7 & $(0.4)$ & 660 & 1.9 & $(0.6)$ & 0.75 \\
\hline $12-18$ & 1,448 & 1.9 & $(0.4)$ & 756 & 1.7 & $(0.6)$ & 692 & 2.1 & $(0.5)$ & 0.65 \\
\hline $19-29$ & 1,543 & 1.5 & $(0.4)$ & 687 & 1.1 & $(0.4)$ & 856 & 2.0 & $(0.6)$ & 0.18 \\
\hline $30-39$ & 2,138 & 1.7 & $(0.3)$ & 898 & 2.1 & $(0.5)$ & 1,240 & 1.2 & $(0.3)$ & 0.09 \\
\hline $40-49$ & 2,197 & 1.0 & $(0.2)$ & 942 & 1.0 & $(0.3)$ & 1,255 & 0.9 & $(0.3)$ & 0.86 \\
\hline $50-59$ & 1,852 & 1.4 & $(0.3)$ & 797 & 1.5 & $(0.4)$ & 1,055 & 1.3 & $(0.4)$ & 0.68 \\
\hline $60-69$ & 1,787 & 1.6 & $(0.3)$ & 776 & 2.2 & $(0.5)$ & 1,011 & 1.1 & $(0.4)$ & 0.07 \\
\hline$\geq 70$ & 1,531 & 1.9 & $(0.5)$ & 622 & 2.2 & $(0.7)$ & 909 & 1.8 & $(0.6)$ & 0.69 \\
\hline
\end{tabular}

Strabismus was defined as a heterotropia at distance and/or near fixation with or without spectacle correction, esodeviation of 10 or more prism diopters, exodeviation of 15 or more prism diopters, or any vertical deviation.

No $=$ number of participants; Prev = prevalence; $\mathrm{SE}=$ standard error.

Table 5. Prevalence of blepharoptosis according to age and gender

\begin{tabular}{|c|c|c|c|c|c|c|c|c|c|c|}
\hline \multirow{2}{*}{ Age group (yr) } & \multicolumn{3}{|c|}{ Total } & \multicolumn{3}{|c|}{ Male } & \multicolumn{3}{|c|}{ Female } & \multirow{2}{*}{$p$-value } \\
\hline & No & Prev (\%) & SE & No & Prev (\%) & $\mathrm{SE}$ & No & Prev (\%) & SE & \\
\hline Total & 14,489 & 11.0 & $(0.8)$ & 6,530 & 12.1 & (0.9) & 7,959 & 10.0 & $(0.8)$ & $<0.01$ \\
\hline $3-5$ & 580 & 9.9 & (1.6) & 313 & 10.1 & (2.1) & 267 & 9.7 & (2.3) & 0.01 \\
\hline $6-11$ & 1,387 & 11.1 & (1.6) & 726 & 13.4 & (2.0) & 661 & 8.6 & (1.5) & $<0.01$ \\
\hline $12-18$ & 1,451 & 9.1 & $(1.2)$ & 757 & 12.5 & (1.7) & 694 & 5.4 & $(0.9)$ & $<0.01$ \\
\hline $19-29$ & 1,546 & 5.0 & $(0.9)$ & 687 & 7.6 & (1.4) & 859 & 2.2 & $(0.7)$ & $<0.01$ \\
\hline 30-39 & 2,141 & 4.1 & $(0.7)$ & 899 & 5.6 & (1.0) & 1,242 & 2.5 & $(0.5)$ & $<0.01$ \\
\hline $40-49$ & 2,203 & 6.7 & $(0.9)$ & 946 & 8.9 & (1.3) & 1,257 & 4.5 & $(0.8)$ & $<0.01$ \\
\hline $50-59$ & 1,853 & 15.0 & (1.5) & 798 & 16.5 & (1.7) & 1,055 & 13.5 & (1.9) & 0.16 \\
\hline $60-69$ & 1,791 & 22.5 & (1.7) & 778 & 20.9 & (2.0) & 1,013 & 24.0 & (1.9) & 0.16 \\
\hline$\geq 70$ & 1,537 & 35.2 & (2.3) & 626 & 33.2 & (2.8) & 911 & 36.4 & (2.6) & 0.26 \\
\hline
\end{tabular}

Blepharoptosis was defined as a marginal reflex distance 1 of $2 \mathrm{~mm}$ or less.

No $=$ number of participants; Prev = prevalence; $\mathrm{SE}=$ standard error.

males, $3.4 \pm 1.4 \%$ in females), and it was higher in females than in males $(p<0.01)$. There were no significant differences in relation to age $(p>0.05)$. The overall prevalence of esodeviation, exodeviation and vertical deviation was $0.2 \pm$ $0.0 \%, 1.1 \pm 0.1 \%$ and $0.3 \pm 0.0 \%$, respectively.

\section{Blepharoptosis}

The overall prevalence of blepharoptosis was $11.0 \pm 0.8 \%$ $(12.1 \pm 0.9 \%$ in males, $10.0 \pm 0.8 \%$ in females) (Table 5 and Fig. 2). The prevalence of blepharoptosis in participants over 


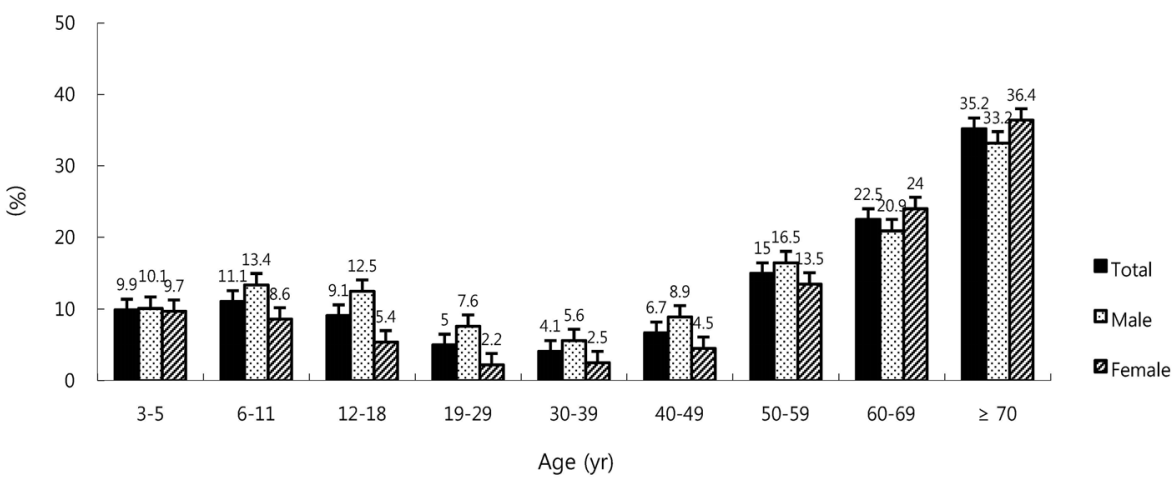

Fig. 2. Prevalence of blepharoptosis according to age and gender.

Table 6. Prevalence of cataract according to age and gender

\begin{tabular}{|c|c|c|c|c|c|c|c|c|c|c|}
\hline \multirow{2}{*}{ Age group (yr) } & \multicolumn{3}{|c|}{ Total } & \multicolumn{3}{|c|}{ Male } & \multicolumn{3}{|c|}{ Female } & \multirow{2}{*}{$p$-value } \\
\hline & No & Prev (\%) & SE & No & Prev (\%) & SE & No & Prev (\%) & SE & \\
\hline Total & 11,037 & 24.1 & $(0.9)$ & 4,718 & 21.9 & $(1.0)$ & 6,319 & 26.2 & $(1.0)$ & $<0.01$ \\
\hline $19-29$ & 1,542 & 1.1 & $(0.3)$ & 685 & 0.9 & $(0.4)$ & 857 & 1.3 & $(0.5)$ & 0.49 \\
\hline $30-39$ & 2,137 & 2.5 & $(0.4)$ & 898 & 2.8 & $(0.7)$ & 1,239 & 2.2 & $(0.4)$ & 0.34 \\
\hline $40-49$ & 2,198 & 10.3 & (1.1) & 943 & 10.6 & (1.3) & 1,255 & 10.0 & (1.3) & 0.66 \\
\hline $50-59$ & 1,850 & 33.8 & $(2.0)$ & 797 & 35.1 & (2.7) & 1,053 & 32.5 & $(2.2)$ & 0.31 \\
\hline $60-69$ & 1,785 & 69.4 & $(2.1)$ & 774 & 67.4 & (2.7) & 1,011 & 71.2 & $(2.2)$ & 0.12 \\
\hline$\geq 70$ & 1,525 & 93.7 & $(0.8)$ & 621 & 90.9 & (1.6) & 904 & 95.4 & (0.8) & $<0.01$ \\
\hline
\end{tabular}

Any cataract in at least one eye: pseudophakic and aphakic eyes were also included as cataract.

No $=$ number of participants; Prev = prevalence; $\mathrm{SE}=$ standard error.

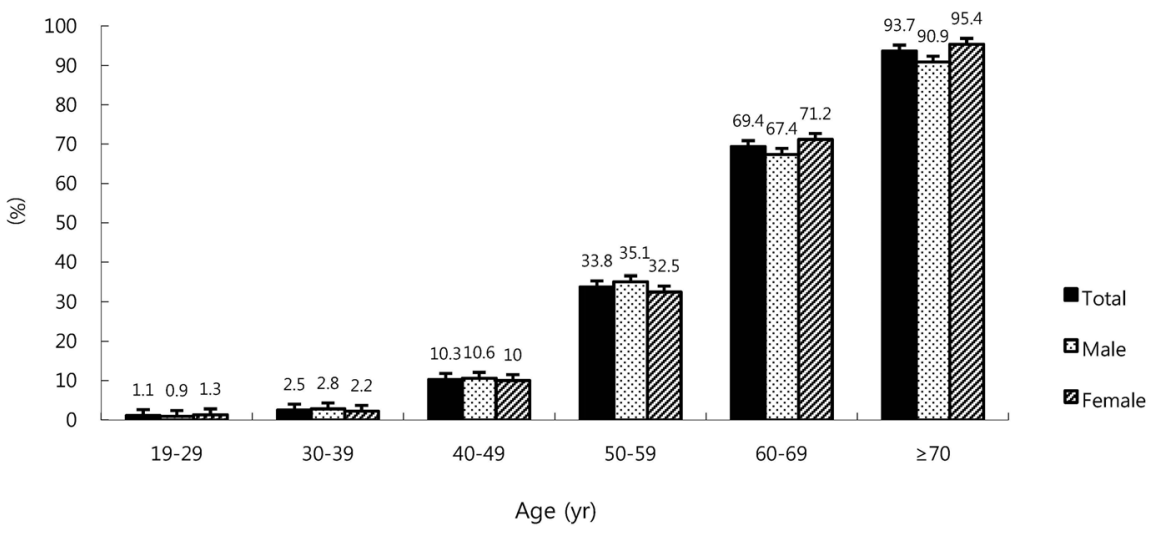

Fig. 3. Prevalence of cataract according to age and gender.
40 years of age was $16.2 \pm 1.1 \%$. From the age of 40 , the prevalence of blepharoptosis was increased with age, and it was highest in the age group over 70 years $(35.2 \pm 2.3 \%, p<$ $0.01)$. The prevalence of blepharoptosis was higher in males than in females in participants from 6 to 49 years of age $(p<$ $0.05)$.

\section{Cataract}

The prevalence of cataract in participants over 19 years of age was $24.1 \pm 0.9 \%(21.9 \pm 1.0 \%$ in males, $26.2 \pm 1.0 \%$ in females) (Table 6 and Fig. 3), that in participants over 40 years of age was $40.2 \pm 1.3 \%(37.5 \pm 1.5 \%$ in males, $42.6 \pm$ $1.3 \%$ in females), and that in participants over 60 years of age was $80.5 \pm 1.3 \%(76.9 \pm 1.8 \%$ in males, $83.2 \pm 1.3 \%$ in females). These results indicate that prevalence of cataract tended to increase with age $(p<0.01)$. The prevalence of cataract in participants over 40 years of age was higher in females than in males $(p<0.01)$.

\section{Pterygium}

The prevalence of pterygium in participants over 19 years of age was $5.4 \pm 0.3 \%(6.1 \pm 0.5 \%$ in males, $4.7 \pm 0.3 \%$ in females) (Table 7 and Fig. 4). The prevalence of pterygium in participants over 40 years of age was $8.9 \pm 0.5 \%(10.1 \pm$ $0.8 \%$ in males, $7.7 \pm 0.5 \%$ in females), while that in participants over 60 years of age was $16.0 \pm 0.8 \%(17.7 \pm 1.3 \%$ in 
Table 7. Prevalence of pterygium according to age and gender

\begin{tabular}{|c|c|c|c|c|c|c|c|c|c|c|}
\hline \multirow{2}{*}{ Age group (yr) } & \multicolumn{3}{|c|}{ Total } & \multicolumn{3}{|c|}{ Male } & \multicolumn{3}{|c|}{ Female } & \multirow{2}{*}{$p$-value } \\
\hline & No & Prev (\%) & SE & No & Prev (\%) & SE & No & $\operatorname{Prev}(\%)$ & SE & \\
\hline Total & 11,014 & 5.4 & $(0.3)$ & 4,716 & 6.1 & $(0.5)$ & 6,298 & 4.7 & $(0.3)$ & $<0.01$ \\
\hline $19-29$ & 1,543 & 0.1 & $(0.1)$ & 685 & 0.1 & $(0.1)$ & 858 & 0.0 & $(0.0)$ & - \\
\hline $30-39$ & 2,130 & 0.9 & $(0.2)$ & 896 & 1.5 & $(0.4)$ & 1,234 & 0.3 & $(0.1)$ & $<0.01$ \\
\hline $40-49$ & 2,192 & 3.9 & (0.6) & 943 & 5.0 & $(0.9)$ & 1,249 & 2.8 & (0.6) & 0.03 \\
\hline $50-59$ & 1,845 & 7.2 & $(0.9)$ & 797 & 9.6 & (1.5) & 1,048 & 4.8 & $(0.7)$ & $<0.01$ \\
\hline $60-69$ & 1,780 & 13.6 & (1.0) & 773 & 14.9 & (1.6) & 1,007 & 12.5 & (1.4) & 0.07 \\
\hline$\geq 70$ & 1,524 & 18.9 & (1.3) & 622 & 21.8 & $(2.2)$ & 902 & 17.1 & (1.5) & 0.07 \\
\hline
\end{tabular}

No $=$ number of participants; Prev = prevalence; $\mathrm{SE}=$ standard error.

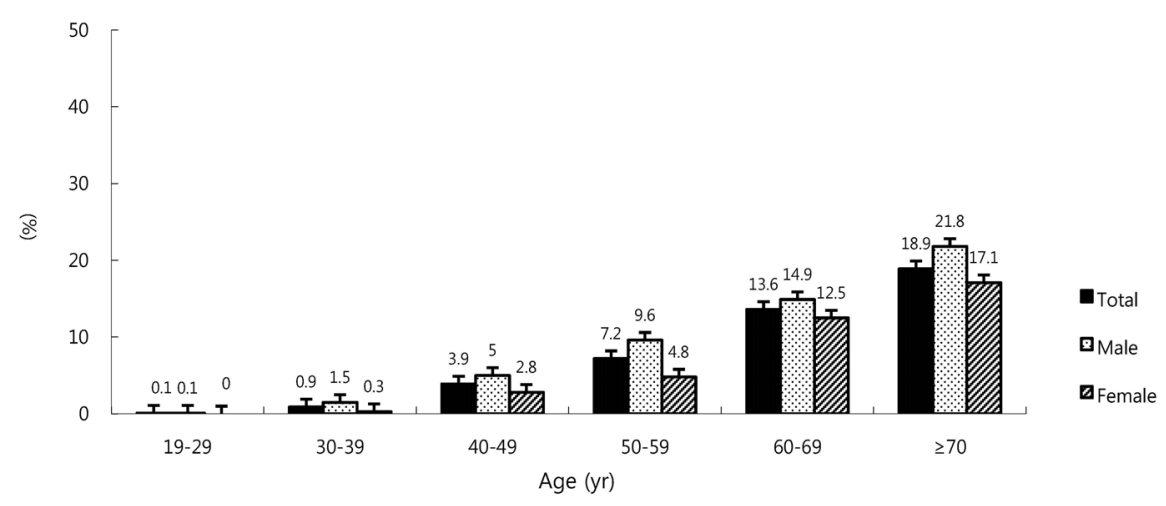

Fig. 4. Prevalence of pterygium according to age and gender.

Table 8. Prevalence of age-related macular degeneration according to age and gender

\begin{tabular}{|c|c|c|c|c|c|c|c|c|c|c|c|c|c|c|c|c|c|c|c|c|}
\hline \multirow{3}{*}{$\begin{array}{l}\text { Age } \\
\text { group } \\
\text { (yr) }\end{array}$} & \multicolumn{9}{|c|}{ Early AMD } & & \multicolumn{9}{|c|}{ Late AMD } & \multirow{3}{*}{ value } \\
\hline & \multicolumn{3}{|c|}{ Total } & \multicolumn{3}{|c|}{ Male } & \multicolumn{3}{|c|}{ Female } & \multirow{2}{*}{$p$-value } & \multicolumn{3}{|c|}{ Total } & \multicolumn{3}{|c|}{ Male } & \multicolumn{3}{|c|}{ Female } & \\
\hline & No & $\begin{array}{l}\text { Prev } \\
(\%)\end{array}$ & SE & No & $\begin{array}{l}\text { Prev } \\
(\%)\end{array}$ & SE & No & $\begin{array}{l}\text { Prev } \\
(\%)\end{array}$ & SE & & No & $\begin{array}{l}\text { Prev } \\
(\%)\end{array}$ & SE & No & $\begin{array}{l}\text { Prev } \\
(\%)\end{array}$ & $\mathrm{SE}$ & No & $\begin{array}{l}\text { Prev } \\
(\%)\end{array}$ & SE & \\
\hline Total & 6,453 & 5.1 & $(0.3)$ & 2,737 & 5.2 & $(0.5)$ & 3,716 & 5.0 & (0.4) & 0.76 & 6,453 & 0.5 & $(0.1)$ & 2,737 & 0.6 & $(0.2)$ & 3,716 & 0.4 & $(0.1)$ & 0.19 \\
\hline $40-49$ & 2,071 & 1.6 & $(0.3)$ & 885 & 1.9 & $(0.5)$ & 1,186 & 1.2 & $(0.4)$ & 0.23 & 2,071 & 0.3 & $(0.1)$ & 885 & 0.5 & $(0.3)$ & 1,186 & 0.0 & $(-)$ & - \\
\hline $50-59$ & 1,706 & 4.1 & $(0.5)$ & 737 & 4.7 & (0.9) & 969 & 3.5 & (0.6) & 0.31 & 1,706 & 0.1 & $(0.1)$ & 737 & 0.2 & $(0.2)$ & 969 & 0.0 & $(-)$ & 0.14 \\
\hline $60-69$ & 1,527 & 8.8 & $(0.9)$ & 660 & 9.6 & (1.4) & 867 & 8.1 & (1.1) & 0.42 & 1,527 & 0.9 & $(0.3)$ & 660 & 0.8 & $(0.3)$ & 867 & 0.9 & $(0.5)$ & 0.84 \\
\hline$\geq 70$ & 1,149 & 13.6 & (1.2) & 455 & 13.3 & (1.8) & 694 & 13.8 & (1.5) & 0.82 & 1,149 & 1.5 & $(0.4)$ & 455 & 1.9 & $(0.7)$ & 694 & 1.3 & $(0.4)$ & 0.38 \\
\hline
\end{tabular}

Patients were defined as having early AMD if they met any one of the following criteria: 1) the presence of soft indistinct drusen or reticular drusen or, 2) the presence of hard or soft distinct drusen with pigmentary abnormalities (increased pigmentation or hypopigmentation of the retinal pigment epithelium) in the absence of signs of late AMD.

$\mathrm{AMD}=$ age-relaged macular degeneration; No. = numberof participants; Prev = prevalence; $\mathrm{SE}=$ standard error.

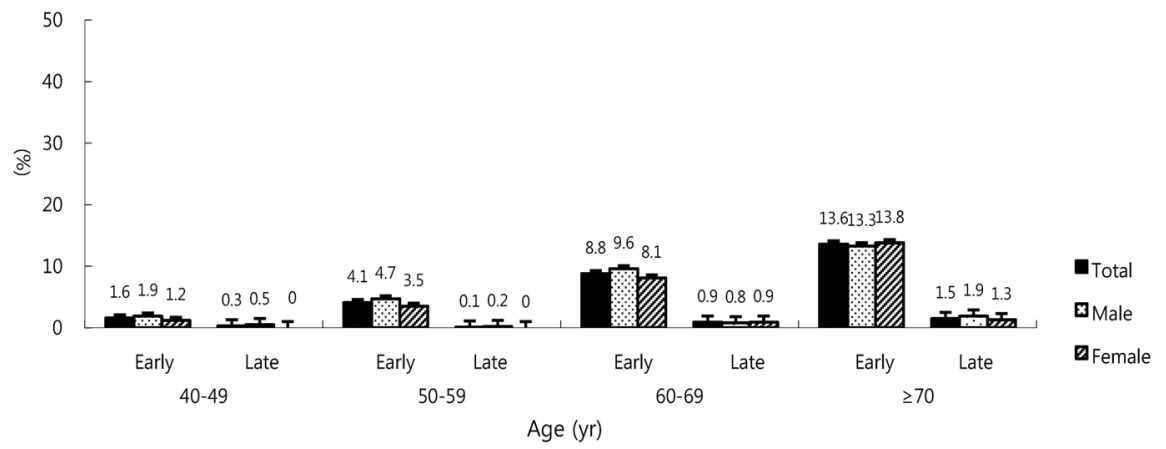

Fig. 5. Prevalence of early and late age-related macular degeneration according to age and gender. males, $14.8 \pm 1.1 \%$ in females). The prevalence of pterygium increased with age $(p<0.01)$. The prevalence of pterygium in participants over 40 years of age was higher in males than females $(p<0.01)$. 
Age-related macular degeneration

The overall prevalence of early AMD over 40 years of age was $5.1 \pm 0.3 \%$ (5.2 $\pm 0.5 \%$ in males, $5.0 \pm 0.4 \%$ in females) (Table 8 and Fig. 5). The prevalence of early AMD in participants over 60 years of age was $10.9 \pm 0.7 \%(10.9 \pm 1.2 \%$ in males, $10.8 \pm 0.9 \%$ in females). The overall prevalence of late AMD over 40 years of age was $0.5 \pm 0.1 \%(0.6 \pm 0.2 \%$ in males, $0.4 \pm 0.1 \%$ in females). The prevalence of late AMD in participants over 60 years of age was $1.1 \pm 0.2 \%(1.2 \pm$ $0.3 \%$ in males, $1.1 \pm 0.3 \%$ in females). The prevalence of AMD increased with age $(p<0.01)$. There were no statistically significant differences in relation to gender $(p>0.05)$.

\section{Diabetic retinopathy}

The prevalence of diabetic retinopathy in participants over 19 years of age was $13.4 \pm 1.5 \%(12.0 \pm 1.9 \%$ in males, 15.1 $\pm 2.2 \%$ in females) (Table 9 and Fig. 6). The prevalence of diabetic retinopathy in participants over 40 years of age was $13.4 \pm 1.5 \%(12.6 \pm 2.0 \%$ in males, $14.3 \pm 2.3 \%$ in females $)$ (Table 9). The prevalence of diabetic retinopathy in participants over 65 years of age was $13.1 \pm 2.4 \%(11.0 \pm 3.0 \%$ in males, $14.5 \pm 3.4 \%$ in females). There were no statistically significant differences in the prevalence of diabetic retinopathy in relation to age or gender $(p>0.05)$.

\section{Glaucoma}

The prevalence of glaucoma in participants over 19 years of age was $1.4 \pm 0.1 \%(1.6 \pm 0.2 \%$ in males, $1.1 \pm 0.2 \%$ in females) (Table 10 and Fig. 7) and was higher in males than in females $(p<0.05)$. The prevalence of glaucoma in participants over 40 years of age was $2.1 \pm 0.2 \%(2.5 \pm 0.3 \%$ in males, $1.7 \pm 0.2 \%$ in females). The prevalence of glaucoma in participants over 60 years of age was $3.3 \pm 0.4 \%$ (3.7 \pm $0.6 \%$ in males, $3.0 \pm 0.5 \%$ in females). In participants over 40 years of age, the prevalence of POAG, PACG and NTG was $2.0 \pm 0.2 \%, 0.1 \pm 0.1 \%$ and $1.9 \pm 0.2 \%$, respectively. The prevalence of glaucoma increased with age $(p<0.01)$. The prevalence of glaucoma was higher in males than in females in participants aged 30 to $49(p<0.05)$.

\section{Discussion}

In the past two decades, several epidemiologic studies have reported on the prevalence of common eye diseases in many countries [2-35,42,43,45-65]. Most of these population-based studies have been conducted in the United States among predominantly White, mixed White and African-American, or Hispanic populations [5-14] or in other countries, including Europe [15-17] and Australia [18-21]. There are a growing number of new population-based studies in Asia, including

Table 9. Prevalence of diabetic retinopathy in persons with diabetes mellitus according to age and gender

\begin{tabular}{|c|c|c|c|c|c|c|c|c|c|c|}
\hline \multirow{2}{*}{ Age group (yr) } & \multicolumn{3}{|c|}{ Total } & \multicolumn{3}{|c|}{ Male } & \multicolumn{3}{|c|}{ Female } & \multirow{2}{*}{$p$-value } \\
\hline & No & Prev (\%) & SE & No & Prev (\%) & SE & No & Prev (\%) & SE & \\
\hline Total & 746 & 13.4 & (1.5) & 352 & 12.0 & (1.9) & 394 & 15.1 & $(2.2)$ & 0.27 \\
\hline $19-29$ & 8 & - & - & 3 & - & - & 5 & - & - & \\
\hline $30-39$ & 33 & - & - & 14 & - & - & 19 & - & - & \\
\hline $40-49$ & 100 & 12.4 & (3.6) & 59 & 12.9 & (5.0) & 41 & 11.5 & (5.1) & 0.85 \\
\hline $50-59$ & 160 & 10.2 & (2.6) & 83 & 7.6 & (2.8) & 77 & 14.6 & (5.2) & 0.21 \\
\hline $60-69$ & 269 & 18.0 & $(2.8)$ & 127 & 20.8 & $(4.2)$ & 142 & 15.2 & (3.2) & 0.26 \\
\hline$\geq 70$ & 176 & 12.3 & (3.1) & 66 & 7.5 & (3.6) & 110 & 14.6 & (4.3) & 0.23 \\
\hline
\end{tabular}

Diabetic retinopathy was defined as the presence of 1 or more retinal microaneurysm or retinal blot hemorrhages with or without more severe lesions (hard exudates, soft exudates, intraretinal microvascular abnormalities, venous bleeding, retinal new vessels, and fibroproliferations). No $=$ number of participants; Prev = prevalence; $\mathrm{SE}=$ standard error.

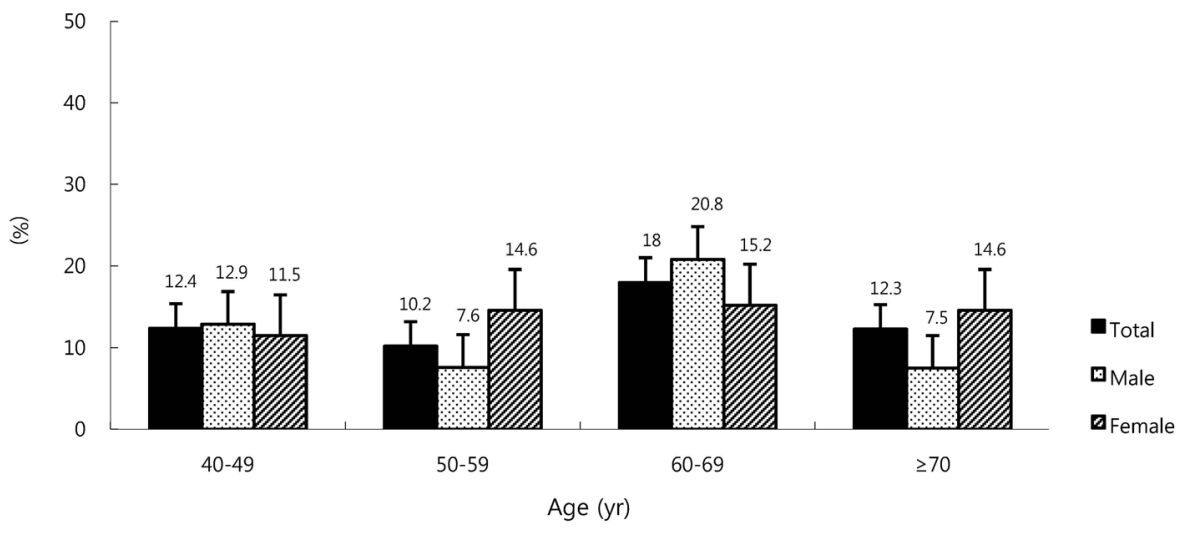

Fig. 6. Prevalence of diabetic retinopathy in persons with diabetes mellitus according to age and gender. 
Table 10. Prevalence of glaucoma according to age and gender

\begin{tabular}{|c|c|c|c|c|c|c|c|c|c|c|}
\hline \multirow{2}{*}{ Age group (yr) } & \multicolumn{3}{|c|}{ Total } & \multicolumn{3}{|c|}{ Male } & \multicolumn{3}{|c|}{ Female } & \multirow{2}{*}{$p$-value } \\
\hline & No & Prev (\%) & SE & No & Prev (\%) & SE & No & $\operatorname{Prev}(\%)$ & SE & \\
\hline Total & 10,035 & 1.4 & $(0.1)$ & 4,284 & 1.6 & $(0.2)$ & 5,751 & 1.1 & $(0.2)$ & $<0.05$ \\
\hline $19-29$ & 1,457 & 0.3 & $(0.1)$ & 646 & 0.1 & $(0.1)$ & 811 & 0.5 & $(0.3)$ & 0.22 \\
\hline $30-39$ & 2,017 & 0.7 & $(0.2)$ & 848 & 1.0 & (0.4) & 1,169 & 0.2 & $(0.1)$ & $<0.01$ \\
\hline $40-49$ & 2,095 & 1.0 & $(0.2)$ & 898 & 1.4 & (0.4) & 1,197 & 0.5 & $(0.2)$ & $<0.05$ \\
\hline $50-59$ & 1,720 & 2.3 & $(0.4)$ & 737 & 2.8 & $(0.7)$ & 983 & 1.9 & $(0.5)$ & 0.20 \\
\hline $60-69$ & 1,585 & 2.2 & $(0.4)$ & 682 & 2.5 & $(0.7)$ & 903 & 1.9 & $(0.5)$ & 0.41 \\
\hline$\geq 70$ & 1,161 & 4.9 & $(0.7)$ & 473 & 5.7 & (1.2) & 688 & 4.4 & $(0.9)$ & 0.40 \\
\hline
\end{tabular}

No $=$ number of participants; Prev = prevalence; $\mathrm{SE}=$ standard error.

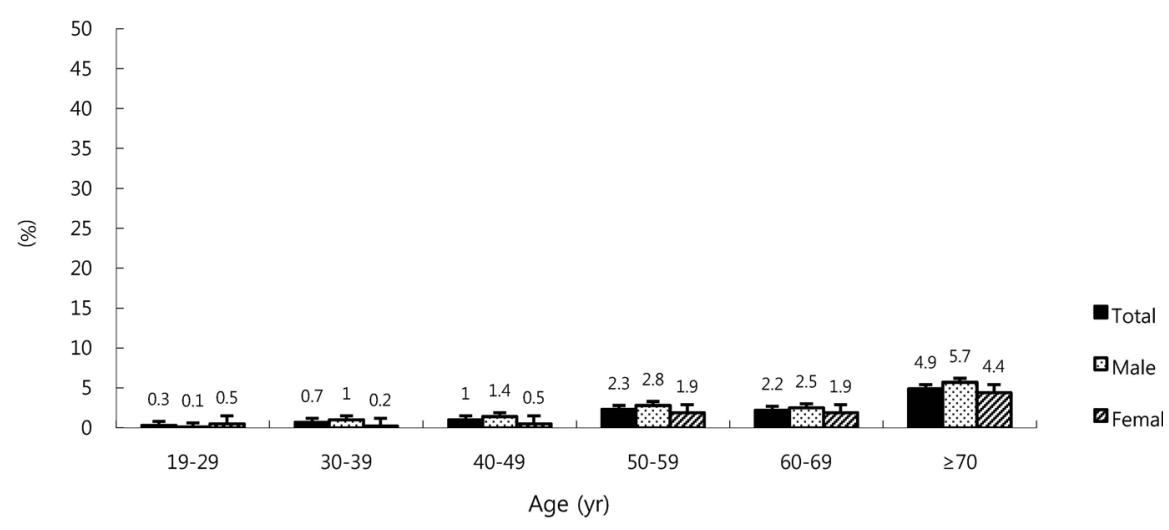

Fig. 7. Prevalence of glaucoma according to age and gender.
Japan [22-26,48,56], Singapore [27-30], China [31-35,46] and Taiwan $[61,62]$. However, even within a single Asian country, significant racial/ethnic variations may exist. The present study is the first investigating the prevalence of eye diseases in South Korea based on nationally representative data.

The 10th Revision of the World Health Organization International Statistical Classification of Diseases, Injuries and Causes of Death defines visual impairment as a BCVA less than 20 / 60 but 20 / 400 or better in the best eye, and blindness is defined as a BCVA of worse than $20 / 400$ in the best eye. The United States criteria define visual impairment as a BCVA of less than $20 / 40$ but better than $20 / 200$, and blindness as a BCVA of $20 / 200$ or worse. Using the United States standard, the prevalence of visual impairment was $0.97 \%$ to $2.34 \%$ in White Americans over 40 years of age [10] and 5.3\% in African Americans over 65 years of age [8]. In a Japanese population of subjects over 40 years of age, the prevalence of visual impairment and blindness were $1.28 \%$ and $0.15 \%$, respectively [25]. The prevalence of visual impairment and blindness in China was reported as $1.1 \%$ and $0.3 \%$, respectively, in subjects over 40 years of age, according to the World Health Organization definition [31]. In our study, when we defined visual impairment and blindness as a BCVA of 0.32 or worse and 0.01 or worse, respectively, the prevalence of visual impairment and blindness in the subjects over 40 years of age was $0.9 \%$ and $0.1 \%$, respectively, similar to the prevalence reported from China.
The prevalence of myopia has been reported as $25 \%$ in Western Europe [45], 26\% in the United States [45], 38\% among Chinese individuals [46], and $41 \%$ to $43 \%$ in Japan $[47,48]$. In the present study, the prevalence of myopia in adult Koreans over 40 years of age was $35.7 \%$, which was higher than those of Western Europe and United States and similar to those reported in China and Japan. Changes in the prevalence and value of refractive errors do occur with age starting in childhood [49]. Many studies have reported a decrease of the prevalence of myopia and a simultaneous increase in the prevalence of hyperopia with increasing age [50-52]. Results of our study were in agreement with those findings.

In this study, the overall prevalence of strabismus in the 3 to 5 and 6 to 11 year age groups was $1.8 \%$ in South Korea. The prevalence of strabismus has been reported as $2.3 \%$ in subjects 2 to 5 years of age in the United Kingdom [53],3.1\% in subjects 4 to 7 years of age in the United States [54], 2.7\% in subjects under the age of 7 years in Sweden [55], and 1.3\% in subjects 6 to 12 years of age in Japan [56]. There is a significant ethnic component influencing the distribution of strabismus: Studies in Asian populations have reported an esotropia to exotropia ratio of less than 1, while in European populations, the ratio was greater than 1 [53-56]. Our study demonstrated an esotropia to exotropia ratio of less than 1, similar to results from other Asian countries [56].

Blepharoptosis, drooping of the upper eyelid, is one of the most common upper eyelid diseases. Symptoms relate to im- 
pairment of the superior visual field and central vision in severe cases. Even though blepharoptosis is generally known to exist below 4 to $5 \mathrm{~mm}$ of $\mathrm{MRD}_{1}$ in Western populations, there are no accurate definitions and available data on the prevalence of blepharoptosis, particularly among Asians. Except for Nigeria, the prevalence of blepharoptosis has not been reported. In the Nigeria study, blepharoptosis was defined as the amount of the cornea covered by more than $2 \mathrm{~mm}$ by the upper eyelid, and the prevalence of blepharoptosis among school children under the age of 16 years was $1.2 \%$ [57]. There are no accurate diagnostic criteria about blepharoptosis for Asian or Korean populations. However, depending on race, there are many differences in facial anatomy. Therefore, we defined blepharoptosis as less than $2 \mathrm{~mm}$ of $\mathrm{MRD}_{1}$ with consideration for anatomical differences of the eyelids and orbit. In our study, the prevalence of blepharoptosis in the 3 to 5,6 to 11 and 12 to 18 age groups were $9.9 \%, 11.1 \%$ and $9.1 \%$, respectively, higher than prevalences reported in Nigeria. One of the main objectives of this study is to estimate the prevalence of blepharoptosis in Koreans. In future studies, appropriate diagnostic criteria should be established for use in Korean people.

The prevalence of cataract has been reported as $22.3 \%$ in the United States [29], 40.4\% in Myanmar [55] and 35.0\% in China [28]. In the present study, the prevalence of cataract in adult Korean over 40 years of age was $40.2 \%$. The prevalence of cataract was similar to those reported in Myanmar and China, where no statistically significant differences in prevalence were observed in relation to gender. However, in the United States and Korea, females showed a significantly higher prevalence of cataract than males.

Several population-based studies have examined the prevalence of pterygium and have indicated a prevalence ranging from $1.2 \%$ in a White population in urban Australia [21] to $33.0 \%$ in a Chinese population of subjects 50 years or older in Doumen County, Southern China [58]. In our study, the prevalence of pterygium in subjects over 40 years of age was $8.9 \%$. Differences in prevalence of pterygium were observed among these studies. However, dominance in male gender and old age associated with formation of pterygium were similar to those observed in other studies.

Large-scale population-based studies have been conducted over the past two decades in order to identify the prevalence and risk factors of AMD [2,6,12,15-19,26,32,60]. Studies have demonstrated variations in the prevalence and risk factors of AMD. In the Blue Mountains Eye Study, the prevalence of early AMD was $8.7 \%$, and the prevalence of late AMD was $1.1 \%$ [19]. In the Beijing Eye Study, the prevalence of early AMD and late AMD was $5.1 \%$ and $0.3 \%$, respectively [32]. In addition, the prevalence of early AMD and late AMD was $3.5 \%$ and $0.5 \%$ in the Funagata Study [26]. In the present study, the prevalence of early AMD and late AMD was $5.1 \%$ and $0.5 \%$, respectively. Our study showed a low prevalence of AMD compared to those in White populations. In addition, the prevalence of AMD in our study was similar to those of Chinese and Japanese populations.

The prevalence of diabetic retinopathy in the United States was reported as $28.5 \%$ to $40.3 \%$ [13,14]. There are many population-based data on the prevalence of diabetic retinopathy in Asia [61-63]. In Taiwan, 35\% of 527 diabetic subjects over 40 years of age had diabetic retinopathy based on clinical examination [61]. However, recent studies in India indicate a much lower prevalence of diabetic retinopathy $[62,63]$. In the present study, the prevalence of diabetic retinopathy (subjects over 40 years of age) was $13.4 \%$, much lower than the prevalence reported in the United States or Taiwan. This relatively low prevalence of diabetic retinopathy may be due to a short duration of diabetes in our study population.

Glaucoma is believed to be the leading global cause of surgically irremediable blindness [64]. In the Baltimore Eye Survey, the prevalence of POAG was approximately four times higher in black people ( $4 \%$ to $5 \%$ ) than in white people $(1.1 \%)$ [65]. In recent years, several studies have been conducted on the epidemiology of glaucoma in Asian people $[22-24,27,66]$. The prevalence ranges of POAG and PACG have been reported as $1.6 \%$ to $3.9 \%$ and $0.4 \%$ to $1.0 \%$, respectively. In this study, the prevalence of POAG and PACG was $2.0 \%$ and $0.1 \%$. The prevalence of POAG was similar to those reported in other Asian countries [22-24,27,66]. In contrast, the prevalence of PACG was lower than those reported in other Asian countries [22-24,27,66]. Results of this study might have been underestimated as only the Van Herick method was used in the diagnosis of PACG.

Accurate epidemiological information may contribute to the proper delivery of health care, preventive screenings, and rehabilitative services to individuals with eye diseases. This study provides standardized protocols for examination of ocular diseases and improvement of ocular examination capacity through education and quality control. Databases containing results from examination of eye diseases and results of quality control can be utilized in future clinical studies. In addition, methodology used in this survey can be utilized as a guideline for use in new population-based studies which will be performed in the nation.

In summary, our nation-wide study demonstrated the prevalence of major eye diseases and potential ocular disease-vulnerable groups in Korea. To the best of our knowledge, this is the first nation-wide epidemiologic study conducted by both the Ophthalmologic Society and the CDC and is a powerful tool for use in investigation of the national prevalence of disease conditions. Further studies are needed using on-going surveys in order to better understand the etiologic or risk factors that may be associated with ophthalmologic diseases and to evaluate proper interventions aimed at prevention of disease-related disabilities.

\section{Conflict of Interest}

No potential conflict of interest relevant to this article was 
reported.

\section{References}

1. Congdon NG, Friedman DS, Lietman T. Important causes of visual impairment in the world today. JAMA 2003;290:2057-60.

2. Song SJ, Youm DJ, Chang Y, Yu HG. Age-related macular degeneration in a screened South Korean population: prevalence, risk factors, and subtypes. Ophthalmic Epidemiol 2009; 16:304-10.

3. Kim JH, Kang SY, Kim NR, et al. Prevalence and characteristics of glaucoma among Korean adults. Korean J Ophthalmol 2011;25:110-5.

4. Kim H, Joo CK. The prevalence and demographic characteristics of anterior polar cataract in a hospital-based study in Korea. Korean J Ophthalmol 2008;22:77-80.

5. Klein R, Klein BE, Lee KE, et al. Changes in visual acuity in a population over a 10-year period: the Beaver Dam Eye Study. Ophthalmology 2001;108:1757-66.

6. Klein R, Klein BE, Linton KL. Prevalence of age-related maculopathy. The Beaver Dam Eye Study. Ophthalmology 1992;99:933-43.

7. Rahmani B, Tielsch JM, Katz J, et al. The cause-specific prevalence of visual impairment in an urban population. The Baltimore Eye Survey. Ophthalmology 1996;103:1721-6.

8. Munoz B, West SK, Rubin GS, et al. Causes of blindness and visual impairment in a population of older Americans: the Salisbury Eye Evaluation Study. Arch Ophthalmol 2000;118: 819-25.

9. Varma R, Paz SH, Azen SP, et al. The Los Angeles Latino Eye Study: design, methods, and baseline data. Ophthalmology 2004;111:1121-31.

10. Congdon N, O'Colmain B, Klaver CC, et al. Causes and prevalence of visual impairment among adults in the United States. Arch Ophthalmol 2004;122:477-85.

11. Congdon N, Vingerling JR, Klein BE, et al. Prevalence of cataract and pseudophakia/aphakia among adults in the United States. Arch Ophthalmol 2004;122:487-94.

12. Friedman DS, O'Colmain BJ, Muin BE, et al. Prevalence of cataract and pseudophakia/aphakia among adults in the United States. Arch Ophthalmol 2004;122:564-72.

13. Kempen JH, O'Colmain BJ, Leske MC, et al. The prevalence of diabetic retinopathy among adults in the United States. Arch Ophthalmol 2004;122:552-63.

14. Zhang X, Saaddine JB, Chou CF, et al. Prevalence of diabetic retinopathy in the United States, 2005-2008. JAMA 2010;304: 649-56.

15. Vingerling JR, Hofman A, Grobbee DE, de Jong PT. Age-related macular degeneration and smoking. The Rotterdam Study. Arch Ophthalmol 1996;114:1193-6.

16. Buch H, Vinding T, la Cour M, et al. Risk factors for age-related maculopathy in a 14-year follow-up study: the Copenhagen City Eye Study. Acta Ophthalmol Scand 2005; 83:409-18.

17. Buch H, Nielsen NV, Vinding T, et al. 14-Year incidence, progression, and visual morbidity of age-related maculopathy: the Copenhagen City Eye Study. Ophthalmology 2005;112: 787-98.

18. Mitchell P, Wang JJ, Smith W, Leeder SR. Smoking and the 5-year incidence of age-related maculopathy: the Blue Mountains Eye Study. Arch Ophthalmol 2002;120:1357-63.

19. Mitchell P, Wang JJ, Foran S, Smith W. Five-year incidence of age-related maculopathy lesions: the Blue Mountains Eye Study. Ophthalmology 2002;109:1092-7.

20. Livingston PM, Carson CA, Stanislavsky YL, et al. Methods for a population-based study of eye disease: the Melbourne Visual Impairment Project. Ophthalmic Epidemiol 1994;1: 139-48.

21. McCarty CA, Fu CL, Taylor HR. Epidemiology of pterygium in Victoria, Australia. Br J Ophthalmol 2000;84:289-92.

22. Yamamoto T, Iwase A, Araie M, et al. The Tajimi Study report 2 : prevalence of primary angle closure and secondary glaucoma in a Japanese population. Ophthalmology 2005;112:1661-9.

23. Iwase A, Suzuki Y, Araie M, et al. The prevalence of primary open-angle glaucoma in Japanese: the Tajimi Study. Ophthalmology 2004;111:1641-8.

24. Miyazaki M, Kubota T, Kubo M, et al. The prevalence of pseudoexfoliation syndrome in a Japanese population: the Hisayama Study. J Glaucoma 2005;14:482-4.

25. Yamada M, Hiratsuka Y, Roberts CB, et al. Prevalence of visual impairment in the adult Japanese population by cause and severity and future projections. Ophthalmic Epidemiol 2010; 17:50-7.

26. Kawasaki R, Wang JJ, Ji GJ, et al. Prevalence and risk factors for age-related macular degeneration in an adult Japanese population: the Funagata Study. Ophthalmology 2008;115: 1376-81, 1381.e1-2.

27. Foster PJ, Oen FT, Machin D, et al. The prevalence of glaucoma in Chinese residents of Singapore: a cross-sectional population survey of the Tanjong Pagar district. Arch Ophthalmol 2000;118:1105-11.

28. Seah SK, Wong TY, Foster PJ, et al. Prevalence of lens opacity in Chinese residents of Singapore: the tanjong pagar survey. Ophthalmology 2002;109:2058-64.

29. Lamoureux EL, Chong E, Wang JJ, et al. Visual impairment, causes of vision loss, and falls: the singapore malay eye study. Invest Ophthalmol Vis Sci 2008;49:528-33.

30. Foong AW, Saw SM, Loo JL, et al. Rationale and methodology for a population-based study of eye diseases in Malay people: The Singapore Malay eye study (SiMES). Ophthalmic Epidemiol 2007; 14:25-35.

31. Xu L, Wang Y, Li Y, et al. Causes of blindness and visual impairment in urban and rural areas in Beijing: the Beijing Eye Study. Ophthalmology 2006;113:1134.e1-11.

32. Li Y, Xu L, Jonas JB, et al. Prevalence of age-related maculopathy in the adult population in China: the Beijing Eye Study. Am J Ophthalmol 2006;142:788-93.

33. Xu L, Li Y, Wang S, et al. Characteristics of highly myopic eyes: the Beijing Eye Study. Ophthalmology 2007;114:121-6.

34. You Q, Xu L, Jonas JB. Prevalence and associations of epiretinal membranes in adult Chinese: the Beijing Eye Study. Eye (Lond) 2008;22:874-9.

35. Liang YB, Friedman DS, Wong TY, et al. Rationale, design, methodology, and baseline data of a population-based study in rural China: the Handan Eye Study. Ophthalmic Epidemiol 2009; 16:115-27.

36. Jin YH. A new logMAR vision chart: Jin's Vision Chart. $J$ Korean Ophthalmol Soc 1997;38:2036-44.

37. Van Herick W, Shaffer RN, Schwartz A. Estimation of width of angle of anterior chamber. Incidence and significance of the narrow angle. Am J Ophthalmol 1969;68:626-9.

38. Tan DT, Chee SP, Dear KB, Lim AS. Effect of pterygium morphology on pterygium recurrence in a controlled trial comparing conjunctival autografting with bare sclera excision. Arch Ophthalmol 1997;115:1235-40.

39. Bird AC, Bressler NM, Bressler SB, et al. An international classification and grading system for age-related maculopathy and age-related macular degeneration. The International ARM Epidemiological Study Group. Surv Ophthalmol 1995; 39:367-74.

40. Diabetic Retinopathy Study Coordinating Center. Diabetic 
Retinopathy Study: mannual of operations. Baltimore: Diabetic Retinopathy Study Coordinating Center; 1972.

41. Early Treatment Diabetic Retinopathy Study Research Group. Grading diabetic retinopathy from stereoscopic color fundus photographs: an extension of the modified Airlie House classification. ETDRS report number 10. Ophthalmology 1991;98(5 Suppl):786-806.

42. Klein R, Klein BE, Moss SE, Cruickshanks KJ. The Wisconsin Epidemiologic Study of diabetic retinopathy. XIV. Ten-year incidence and progression of diabetic retinopathy. Arch Ophthalmol 1994;112:1217-28.

43. Klein R, Klein BE, Moss SE, Cruickshanks KJ. The Wisconsin Epidemiologic Study of Diabetic Retinopathy: XVII. The 14-year incidence and progression of diabetic retinopathy and associated risk factors in type 1 diabetes. Ophthalmology 1998;105:1801-15.

44. Foster PJ, Buhrmann R, Quigley HA, Johnson GJ. The definition and classification of glaucoma in prevalence surveys. Br J Ophthalmol 2002;86:238-42.

45. Kempen JH, Mitchell P, Lee KE, et al. The prevalence of refractive errors among adults in the United States, Western Europe, and Australia. Arch Ophthalmol 2004;122:495-505.

46. Wong TY, Foster PJ, Hee J, et al. Prevalence and risk factors for refractive errors in adult Chinese in Singapore. Invest Ophthalmol Vis Sci 2000;41:2486-94.

47. Shimizu N, Nomura H, Ando F, et al. Refractive errors and factors associated with myopia in an adult Japanese population. Jpn J Ophthalmol 2003;47:6-12.

48. Sawada A, Tomidokoro A, Araie M, et al. Refractive errors in an elderly Japanese population: the Tajimi study. Ophthalmology 2008;115:363-70.e3.

49. Gwiazda J, Scheiman M, Mohindra I, Held R. Astigmatism in children: changes in axis and amount from birth to six years. Invest Ophthalmol Vis Sci 1984;25:88-92.

50. Mutti DO, Zadnik K. Age-related decreases in the prevalence of myopia: longitudinal change or cohort effect? Invest Ophthalmol Vis Sci 2000;41:2103-7.

51. Katz J, Tielsch JM, Sommer A. Prevalence and risk factors for refractive errors in an adult inner city population. Invest Ophthalmol Vis Sci 1997;38:334-40.

52. Anton A, Andrada MT, Mayo A, et al. Epidemiology of refractive errors in an adult European population: the Segovia study. Ophthalmic Epidemiol 2009;16:231-7.

53. Robaei D, Rose KA, Kifley A, et al. Factors associated with childhood strabismus: findings from a population-based study. Ophthalmology 2006;113:1146-53.

54. Preslan MW, Novak A. Baltimore Vision Screening Project. Ophthalmology 1996;103:105-9.

55. Kvarnstrom G, Jakobsson P, Lennerstrand G. Visual screening of Swedish children: an ophthalmological evaluation. Acta Ophthalmol Scand 2001;79:240-4.

56. Matsuo T, Matsuo C. The prevalence of strabismus and amblyopia in Japanese elementary school children. Ophthalmic Epidemiol 2005;12:31-6.

57. Baiyeroju AM, Oluwatosin OM. Blepharoptosis in Ibadan, Nigeria. West Afr J Med 2003;22:208-10.

58. Athanasiov PA, Casson RJ, Sullivan T, et al. Cataract in rural Myanmar: prevalence and risk factors from the Meiktila Eye Study. Br J Ophthalmol 2008;92:1169-74.

59. Wu K, He M, Xu J, Li S. Pterygium in aged population in Doumen County, China. Yan Ke Xue Bao 2002;18:181-4.

60. Chen SJ, Cheng CY, Peng KL, et al. Prevalence and associated risk factors of age-related macular degeneration in an elderly Chinese population in Taiwan: the Shihpai Eye Study. Invest Ophthalmol Vis Sci 2008;49:3126-33.

61. Chen MS, Kao CS, Chang CJ, et al. Prevalence and risk factors of diabetic retinopathy among noninsulin-dependent diabetic subjects. Am J Ophthalmol 1992;114:723-30.

62. Narendran V, John RK, Raghuram A, et al. Diabetic retinopathy among self reported diabetics in southern India: a population based assessment. Br J Ophthalmol 2002;86:1014-8.

63. Rema M, Premkumar S, Anitha B, et al. Prevalence of diabetic retinopathy in urban India: the Chennai Urban Rural Epidemiology Study (CURES) eye study, I. Invest Ophthalmol Vis Sci 2005;46:2328-33.

64. Thylefors B, Negrel AD, Pararajasegaram R, Dadzie KY. Global data on blindness. Bull World Health Organ 1995; 73:115-21

65. Tielsch JM, Sommer A, Katz J, et al. Racial variations in the prevalence of primary open-angle glaucoma. The Baltimore Eye Survey. JAMA 1991;266:369-74.

66. Rahman MM, Rahman N, Foster PJ, et al. The prevalence of glaucoma in Bangladesh: a population based survey in Dhaka division. Br J Ophthalmol 2004;88:1493-7. 